\title{
LA PATOLOGIA Y EL LENGUAJE. INFORMES DE PATOLOGIA
}

\author{
(THE PATHOLOGY AND THE LANGUAGE. PATHOLOGY REPORTS)
}

Alvaro García Meseguer, Doctor Ingeniero

Profesor de Investigación IETCC, CSIC

\section{RESUMEN}

Se exponen unas reflexiones sobre cuál debe ser el contenido y la estructuración de un dictamen de patología, haciendo énfasis en los aspectos lingüísticos del asunto. Se incluyen también algunos consejos de actuación para patólogos de poca experiencia. Finalmente, se presentan ejemplos en los que la causa de los daños parece ligada a fenómenos psicolingüisticos, según la teoría de Sapir-Whorf que establece conexiones directas entre lenguaje, pensamiento y realidad, con el consiguiente reflejo en el comportamiento humano.
SUMMARY

Reflections are made about what the contents and the organization of a pathology report must be, including some advices for pathologists of short experience. On the other hand, a few examples are given, where the cause of the damages seems to be related with psycolinguistic phenomena, according to the

theory of Sapir-Whorf which establish direct connections between language, thought and reality, having direct consequences in human behaviour.

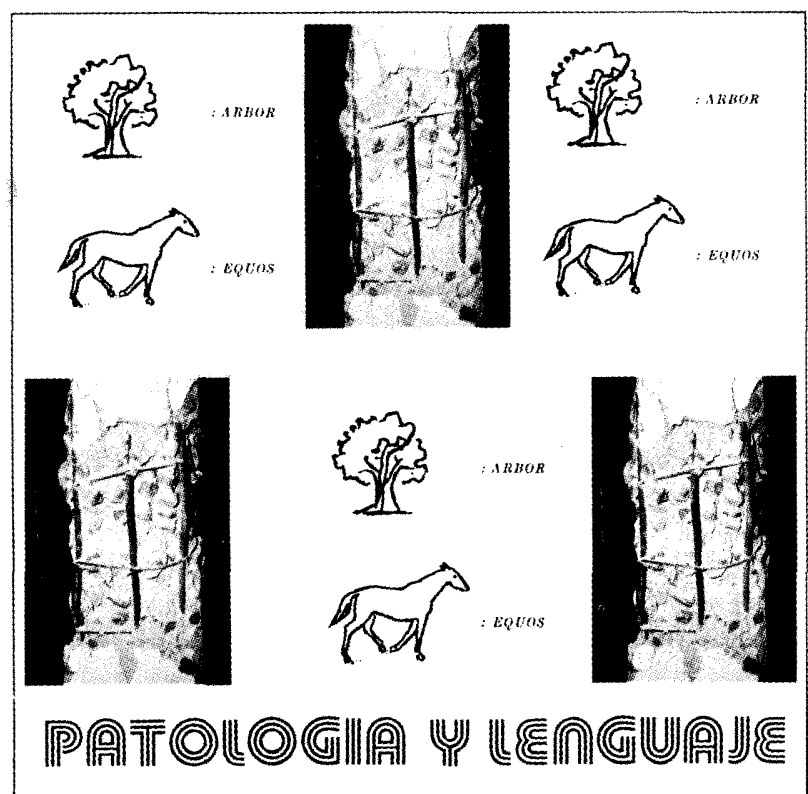

\section{INTRODUCCION}

La Patología como rama de la Ingeniería Estructural - o, más ampliamente, de la Ciencia y Técnica de la Construcción- no constituye todavía una discipli- na normalizada; es de suponer que no tardará mucho en constituirse como tal. En efecto, cada vez son más numerosos quienes se dedican profesionalmente a ella en todo el mundo, así como las publicaciones, cursos, congresos, etc., que se organizan sobre la materia.

¿Qué relaciones pueden existir entre la patología y el lenguaje? Hay al menos dos que se me ocurran. La primera, más superficial, es que el patólogo tiene que acabar emitiendo un informe, lo cual requiere describir con palabras una situación técnica que, a menudo, aparece confusa; pudiendo tener, además, repercusiones en la responsabilidad profesional de otros colegas. La segunda, más profunda, es que el lenguaje impone unas categorías al pensamiento, por lo que pudiera suceder (y yo creo que, de hecho, sucede) que la causa de los daños, en algún caso, esté ligada a fenómenos lingüísticos.

A continuación me referiré al primer aspecto indicado (Parte I) dirigiéndome en especial a jóvenes patólogos de poca experiencia. Trataré después brevemente (Parte II) el segundo aspecto, que me parece puede tener un interés más general. 


\section{PARTE I.-INFORMES DE PATOLOGIA}

\section{Informes y dictámenes}

Un informe es un desarrollo con explicaciones de un reconocimiento. Un dictamen es una opinión emitida por un experto acerca de algo que se somete a su juicio. En las tarifas de los colegios profesionales, los dictámenes se valoran más que los informes (tarifa doble, en general), lo cual es un reflejo de la mayor responsabilidad del autor.

En el lenguaje común suelen entremezclarse ambos conceptos, cosa que no es extraña, ya que muy a menudo los informes contienen opiniones y los dictámenes incluyen descripciones y reconocimientos. Por ello, en este trabajo me referiré al caso más general de informe-dictamen, y emplearé así mismo la voz expediente para referirme a uno $u$ otro.

Hay un caso claro que da origen a un dictamen: aquél en que, a partir de unos datos que se facilitan al experto, se pide a éste que conteste por escrito a una serie de preguntas. En este caso, el experto trabaja sobre papeles únicamente en una labor de gabinete, situación ésta que a menudo deriva de algún litigio judicial. Con frecuencia, las preguntas que llegan al experto han sido formuladas por una persona que no tiene conocimientos técnicos; o han sido redactadas por un técnico pero no son las más adecuadas para el fin que se persigue. En tales casos, si el profesional puede influir en la redacción de las preguntas mismas, conviene que lo haga en aras de una mayor claridad y eficacia de su dictamen.

\section{La ética del patólogo}

En patología son pocas las veces en que la situación es de una claridad meridiana. La obligación del patólogo es reflejar la situación tal y como él la ve, con sus luces y sus sombras. Pero claro, describir (y más aún, cuantificar) las luces y las sombras es tarea difícil, por lo que antes o después aparecerán en el horizonte dudas de carácter ético, especialmente cuando existen partes en litigio: ¿Hasta que punto es verdad lo que digo en esta frase? ¿No será más verdad, o al menos igual verdad, decir la frase contraria? Estas dos interrogantes sirven para ejemplificar las dudas a las que me refiero.

En mi opinión, conviene distinguir dos casos para descubrir algún criterio orientador. Es obvio que partimos de la base de que el patólogo dirá siempre lo que su leal saber y entender le dicte, sin tergiversar la verdad ni presentarla de forma que llame a engaño. Pero aun así, pueden subsistir dudas en la práctica (zonas de sombra) y es por ello que debemos distinguir dos casos.

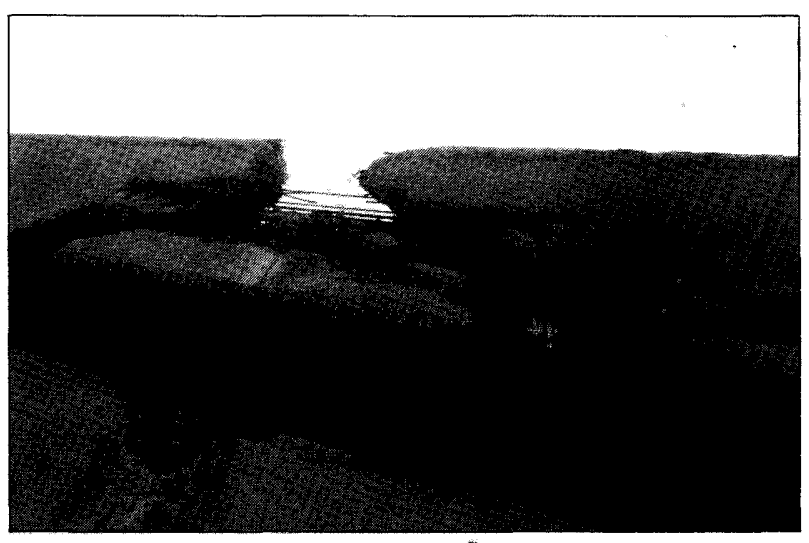

Patologia por impactos (cortesia de INTEMAC).

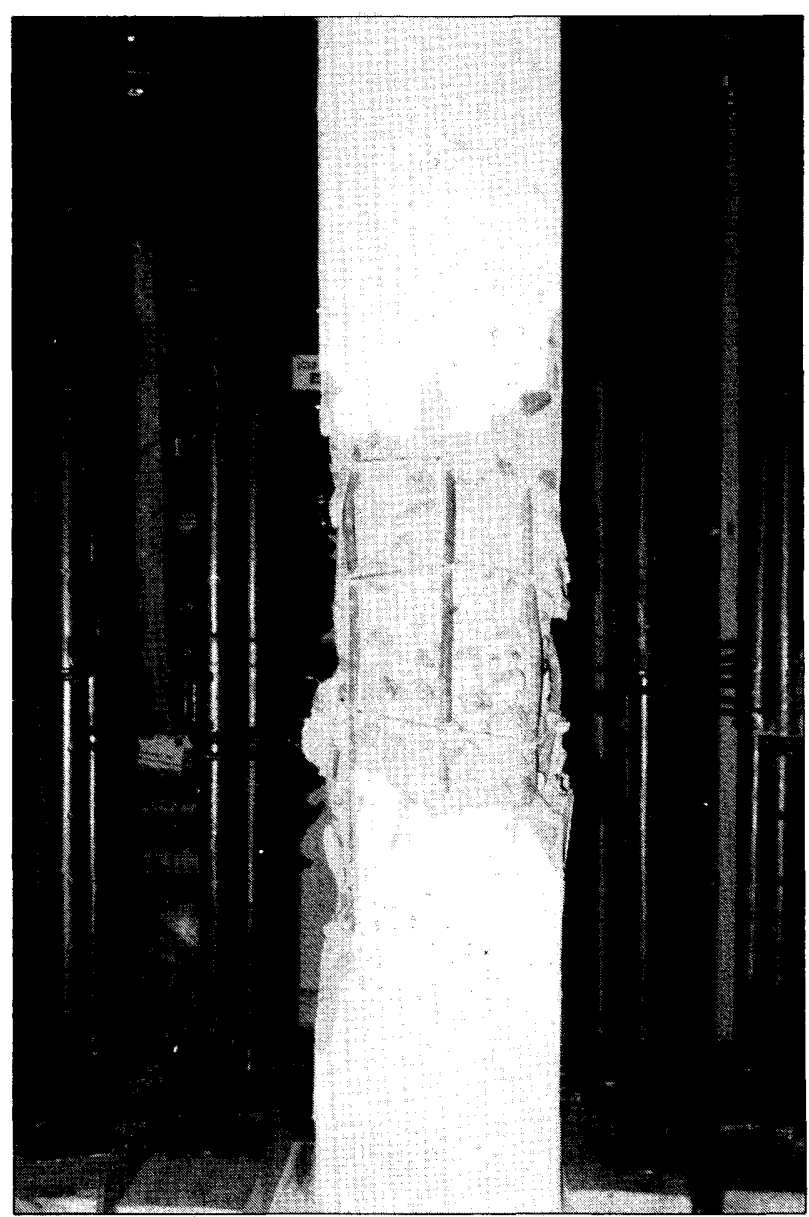

Agotamiento de un pilar (cortesía de INTEMAC).

Cuando el patólogo actúa como árbitro entre dos partes (por acuerdo amistoso o por otro origen), así como si actúa a requerimiento de juez «para mejor proveer», es claro que debe ser absolutamente imparcial. Este caso apenas plantea conflictos éticos: el patólogo analiza los dos puntos de vista y emite su parecer, otorgando a cada uno la parte de razón que él estime que cada uno tiene.

Por el contrario, cuando el patólogo actúa a instancia de una parte la situación cambia. Aclaremos an- 


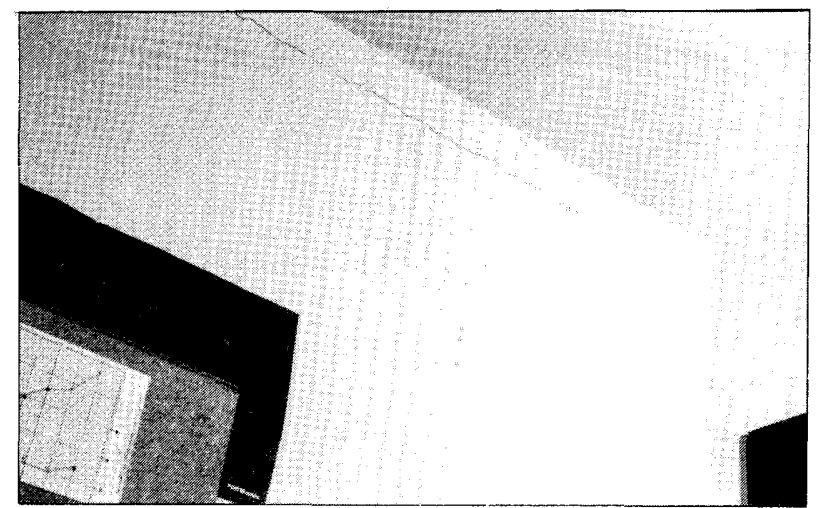

Despegue de tabique.

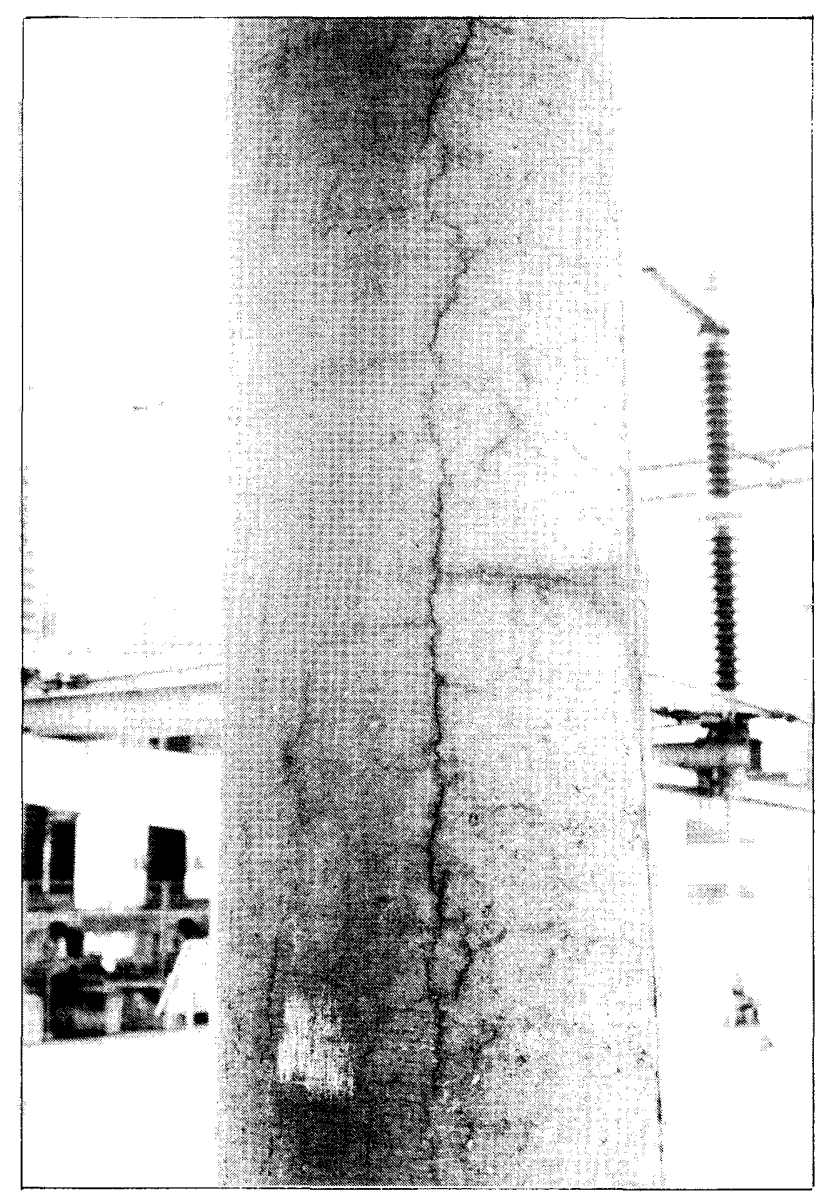

Una fisura tipica de corrosión en soporte.

tes que su actuación puede venir solicitada también por vía judicial, pero ello no significa que necesariamente él sea un perito del juez (caso anterior, para mejor proveer), sino que, simplemente, el juez le da trasládo del deseo de una de las partes de que actúe como perito, deseo que él autoriza como juez dentro del período de prueba del sumario. En tales casos, el interesado puede aceptar o rechazar el encargo y, de aceptarlo, puede pactar con la parte las condiciones, económicas y otras, de su actuación. Además, existirá normalmente otro experto actuando como perito de la otra parte.
En esta situación en la que, a diferencia de la anterior, el experto aparece ligado a una de las partes, la ética del patólogo consiste a mi juicio en decir la verdad, toda la verdad y nada más que la verdad (esto es obvio), pero presentando las zonas de sombra de manera que no perjudiquen a su cliente. Al actuar de igual modo el perito contrario, el juez o árbitro encontrará ante sí los elementos suficientes para fallar en justicia.

En resumen cabría decir que, en el primer caso, el criterio consiste en decir la verdad imparcial y, en el segundo, la verdad leal.

Lo dicho no es fácil de aplicar y requiere poseer un buen repertorio de recursos lingüísticos, algunos de los cuales se apuntarán a lo largo de este artículo. A título de primer ejemplo, diré que yo mismo acabo de utilizar uno en el párrafo anterior, al explicar la ética del perito de parte. Si el lector no ha experimentado ninguna sensación de rechazo moral en lo que ha venido leyendo, es señal de que el recurso ha funcionado.

Me explico. Acabo de decir que la ética del perito de parte reside en «decir la verdad pero presentando las zonas de sombra de manera que no perjudiquen a su cliente». Si en vez de escribir que no perjudiquen hubiese escrito que beneficien a su cliente (que fue, por cierto, la primera idea que me vino a la mente) habría yo incurrido en ligereza, dando pie a que más de un lector hubiese pensado que beneficiar al cliente no es siempre ético. En cambio, nadie discutirá que no perjudicar al cliente sí es de recibo.

Este juego lógico-lingüístico que acabo de exponer, es decir, la diferencia que existe entre afirmar una cosa y negar su contraria, es de importancia capital a la hora de redactar expedientes difíciles.

\section{Estructuración de un informe de patología}

A diferencia de lo que sucede con otros trabajos del experto en estructuras, los informes de patología son utilizados y leídos por personas que no pertenecen al campo profesional. Por ello conviene que su estructuración y redacción sean lo más claras posible, ordenando bien el discurso y teniendo en mente a un lector imaginario del siguiente perfil: no técnico, culto e inteligente.

Un posible índice del informe es el siguiente:

1. Antecedentes y objeto.

2. Inspección ocular.

3. Toma de datos.

4. Descripción de los daños.

5. Análisis y cálculos realizados.

6. Causas posibles. 


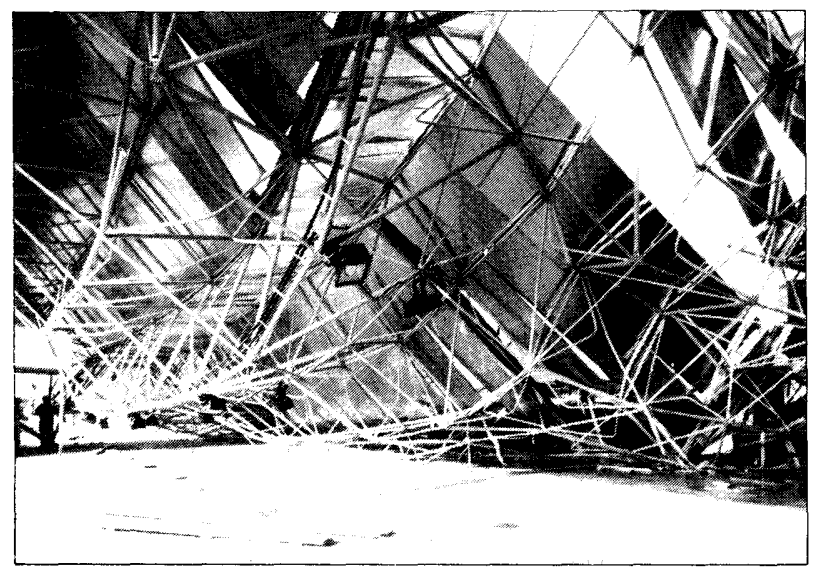

Hundimiento de cubierta metálica.

7. Recomendaciones de actuación.

8. Conclusiones.

En lo que sigue, comentaré el contenido de cada uno de estos apartados.

\section{Apartado 1.-Antecedentes y objeto}

Una forma clásica de arrancar, cuando el autor habla en nombre de un centro u organismo, es la siguiente:

Con fecha... se recibe en este Centro el siguiente escrito:

procediéndose luego a transcribir, entre comillas, el escrito en cuestión.

En este primer apartado deben figurar todos aquellos datos y actuaciones correspondientes a la fase previa del problema, es decir, lo que se comunicó al patólogo como planteamiento del asunto. Los datos que se obtengan con posterioridad vendrán reseñados en el apartado 3 .

En particular, se reseñan:

- Lista de documentos facilitados.

- Mención a reuniones y contactos previos mantenidos.

- Muestras recibidas, si es el caso.

Cuando se han recibido muestras hay que prestar una atención particular, especialmente si se trata de un asunto en litigio. Conviene tomar fotografías, tanto del paquete recibido como de su contenido, acompañando dichas fotografías al informe. Es mejor colocarlas al final y no intercaladas, con objeto de que el ejemplar encuadernado sea más manejable, ya que las fotos requieren un soporte en cartulina diferente de las hojas ordinarias.
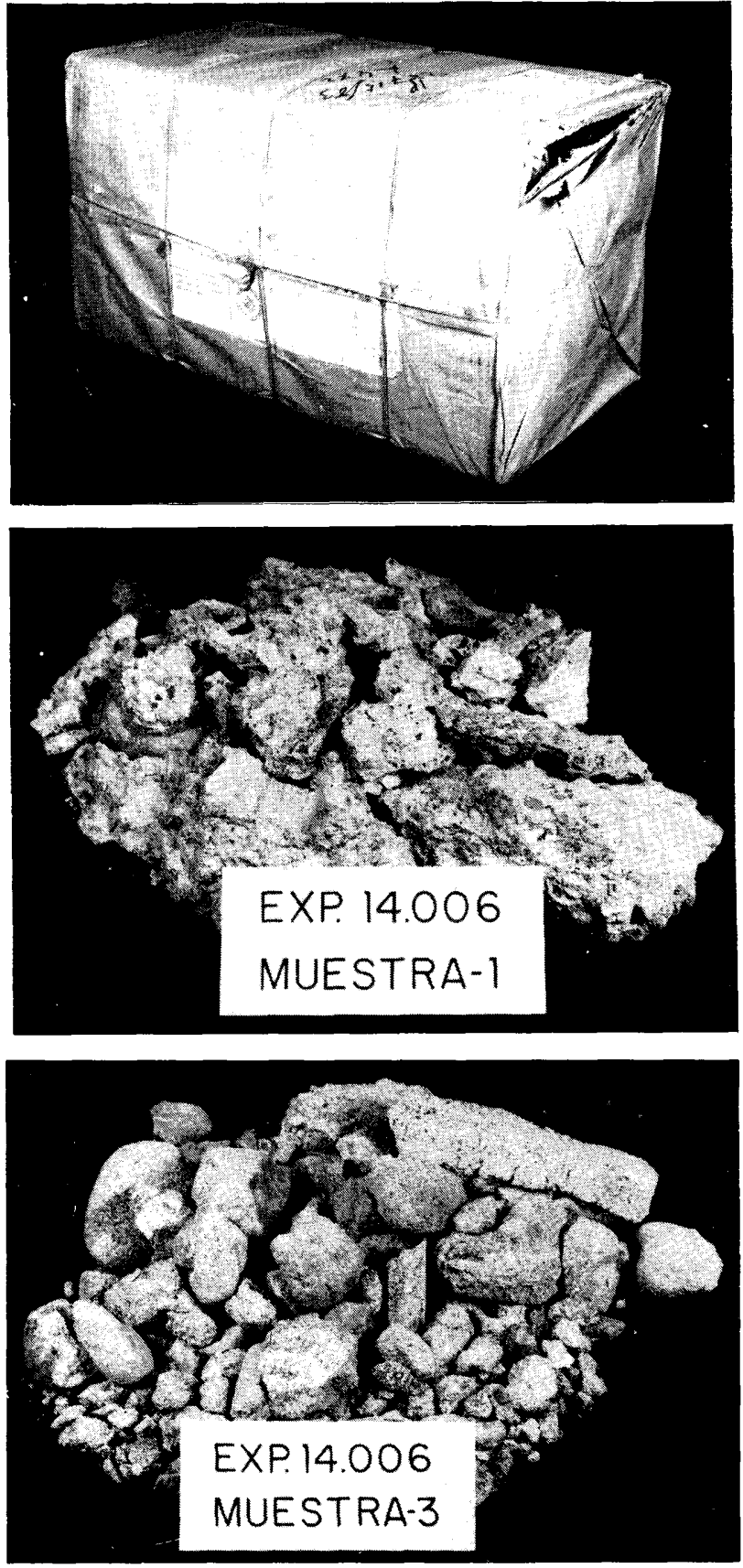

Un ejemplo de muestras recibidas.

Si la lista de documentos facilitados fuese larga y se quisiera destacarlos, podría constituir por sí sola un apartado (sería el número 2 ) bajo el título "Documentación facilitada». Cuando el dictamen se redacta teniendo como base esta documentación única y exclusivamente, merece la pena hacerlo constar así al final de este apartado.

Puede ocurrir que, para la buena comprensión del informe, convenga exponer al principio algunas consideraciones de carácter general. Este recurso es útil cuando el informe va destinado a personas no expertas en el campo estructural (como pueden ser la propiedad o gentes del foro) ya que tiene la ventaja de ir introduciendo al lector poco a poco 
en el ámbito que interesa, así como de permitir que la literatura posterior pueda ser más directa, sin explicaciones intercaladas que distraerían del hilo principal. Para tales casos, pues, se recomienda introducir un tercer apartado que puede titularse "Consideraciones previas» y subdividirse en puntos con títulos adecuados.

Por cierto que el criterio de numeración de apartados también tiene su importancia. Un criterio de clasificación decimal con número árabes, sin sobrepasar los tres o cuatro escalones, es, sin duda, el mejor. La numeración romana sólo conviene para separar grandes sectores o partes del expediente. No deben hacerse coincidir números de análogo valor cuya sola diferencia sea la de ser árabes o romanos ya que, a la hora de citarlos verbalmente, pueden originar confusión u obligar al empleo de expresiones molestas, tales como: "en el apartado dos romano uno se dice...».

Cuando, en el cuerpo de un apartado, se incluyen relaciones o listas, se preferirá identificarlas (si fuese necesario hacerlo; otras veces basta con guiones) con letras (yo prefiero las minúsculas) para dar un poco de variedad, en beneficio y descanso del lector. Otro recurso es emplear la i minúscula, sobre todo en relaciones cortas, al estilo de:

i) contenido en cemento;

ii) relación agua/cemento, y

iii) tamaño máximo del árido.

El final del apartado Antecedentes debe contener un párrafo que explique cuál es el objeto del informe. En casos complicados o de especial responsabilidad este párrafo merecerá los honores de constituirse en Apartado y deberá ser escrito con particular escrupulosidad, puesto que en él se definen los límites y alcance dentro de los cuales deberá ser valorado el expediente. Recordemos que la definición de objeto en el DRAE es, en su cuarta acepción, fin o intento a que se dirige o encamina una acción $u$ operación.

\section{Apartado 2.-Inspección ocular}

La intervención del patólogo suele exigir una o más visitas a la obra dañada. La descripción de estas visitas constituye el objeto de este apartado.

Comencemos por el principio. Para entrar en una obra necesitamos el permiso del director de obra, si está en construcción, o del propietario si está acabada. No es la primera vez que un experto ha tenido que volverse con los bolsillos vacíos porque se le ha negado la entrada. Atención pues a este extremo que no es tan trivial como parece, sobre todo cuando hay litigios de por medio.
El segundo aspecto es quién te lleva a la obra. Lo ideal es ir de la mano de las dos partes, o, al menos, de una con conocimiento de la otra. Atención al posible clima de hostilidad que pueda uno encontrarse, por parte de usuarios (caso de viviendas con lesiones), de obreros, etc., ya que, inevitablemente, el patólogo será identificado por la gente con la persona que le acompañe y, si ésta es considerada culpable de la situación, la hostilidad recaerá también sobre el inocente experto (1).

Atención también a la información verbal que se nos suministre y a las zonas de la obra que nos hagan visitar: siempre habrá otra información que no se nos suministre y otras zonas de obra que no se nos muestren.

A menudo el patólogo es asediado a preguntas in situ. Sin llegar a tanto, rara es la obra en la que no se te pide, cuando menos, "una primera impresión». Hay que ir preparados para ello y no caer en la trampa. Toda discreción es poca, los problemas pueden ser más complicados de lo que a primera vista parezcan y no debemos arriesgarnos a cometer una ligereza. Por otro lado, si ya hemos detectado la causa, lo inteligente es guardar el secreto y no ceder la baza informativa tan fácilmente. Por todo ello, recomiendo atenerse a la vieja regla de oro: ver, oír y callar. En este turno, el que pregunta es el patólogo.

Si el acoso se hiciese insostenible, una forma de zanjar tan enojosa situación (tanto más enojosa cuanto mayor sea nuestra ignorancia sobre el caso) podría ser un discurso como éste: «Mire Vd., yo vengo solamente a realizar una primera inspección ocular. Queda mucho por hacer: tomar muestras, analizar, estudiar el proyecto... Hasta poder dar un diagnóstico, queda un largo camino por andar».

Por el contrario, el patólogo debe esforzarse con habilidad en obtener la máxima información de sus acompañantes, incluidas posibles explicaciones técnicas. No es difícil conseguirlo, pues los humanos en estas circunstancias suelen ser locuaces, sea por espíritu de ayuda, sea por vanidad.

A la hora de reflejar en el informe la visita de inspección deberá prestarse atención a no dar como afirmación propia lo que no fue más que el testimonio de otra persona. Así, por ejemplo:

A) "Las humedades aparecieron hace tres meses» (MAL).

B) «Según manifestación del propietario, las humedades aparecieron...» (BIEN).

(1) Repárese en que la voz inocente está empleada aquí en su doble acepción de «libre de culpa» y "cándido, sin malicia, fácil de engañar». 
10

\section{Apartado 3.-Toma de datos}

Tras una primera visita de inspección puede resultar necesaria la realización de una toma de datos completa, a cargo de un equipo especializado: esclerometría, ultrasonidos, probetas testigo, etc. cuando está en duda la calidad de los hormigones; levantamiento de croquis, marcando con fidelidad las fisuras existentes; rozas para comprobar posición de armaduras, etc. Todas estas actuaciones deben reseñarse en este apartado $3 .^{\circ}$, cuyo contenido es más técnico que literario.

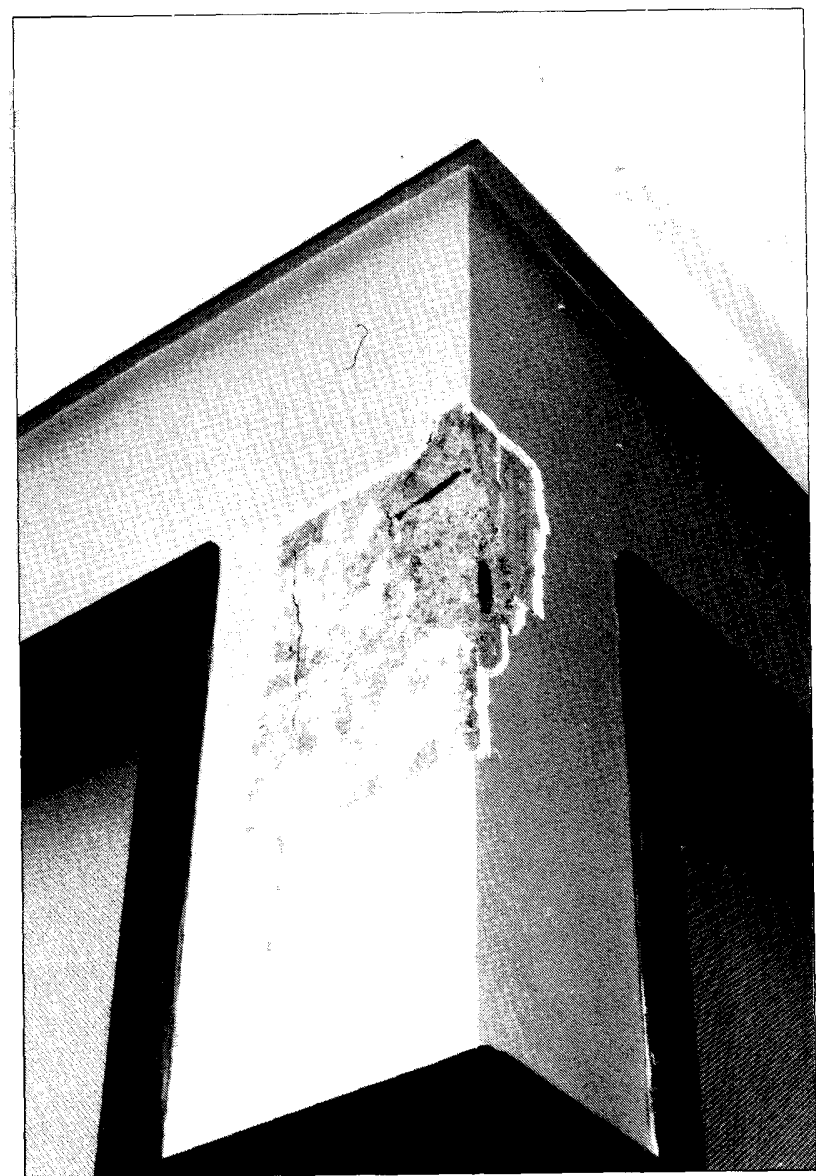

Una cala en zona de fisura.

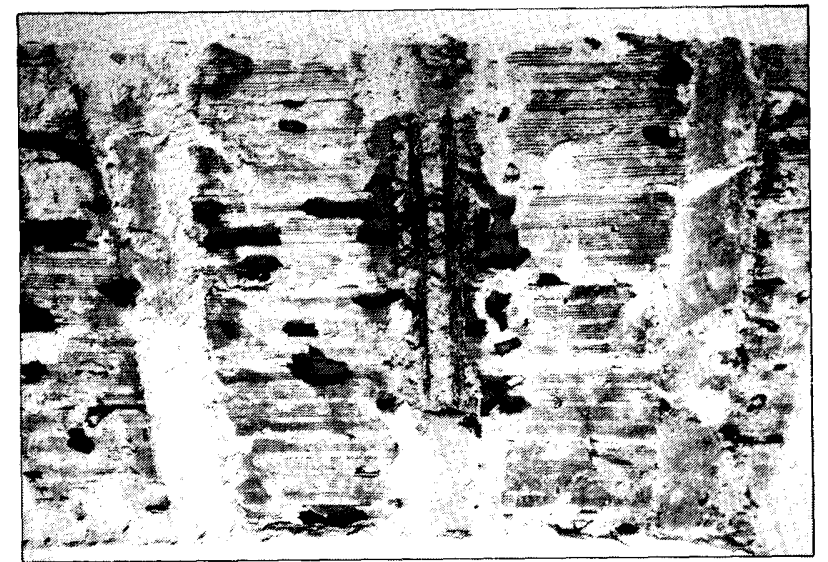

Una cala en vigueta de forjado.
Para evitar una lectura fatigosa, los listados, tablas, etc., deben llevarse a un Anejo, dejando en el cuerpo principal tan sólo aquella información que consideremos relevante.

Este apartado es puramente descriptivo y no debe contener - todavía no es la hora- juicios de valor acerca de los resultados. A lo más, en la descripción podría deslizarse con habilidad algún adjetivo calificativo en el sentido que convenga a nuestro propósito, pero suave y de ningún modo contundente, para no adelantar acontecimientos.

\section{Apartado 4.-Descripción de los daños}

A diferencia del anterior, este es un apartado más bien literario. En su redacción debe recordarse que nuestro lector imaginario es culto e inteligente, pero no técnico.

Es el momento de describir las lesiones (sin aludir a las causas, hay que tener paciencia) de forma minuciosa, arropada con un lenguaje preciso que huya de la vulgaridad, un lenguaje científico que no criptico ni pedante. Debe pensarse que el peticionario ya conoce los daños (si no todos, al menos los aparentes) por lo que no leerá este apartado desde el vacío sino haciendo una comparación mental entre lo que lee y lo que recuerda de la obra real. Se trata por ello de describir lo que ya conoce, precisando y matizando las descripciones, sin estorbar la lectura con planos complicados u otro material (que debe figurar en Anejos) sino, antes bien, facilitándola con figuras y croquis sencillos.
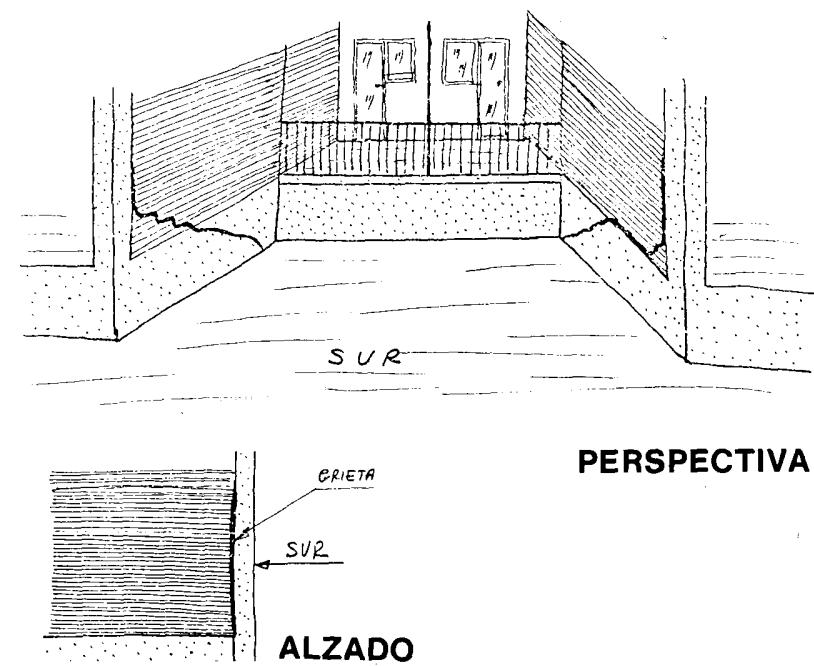

PERSPECTIVA

Descripción en croquis de las lesiones observadas.

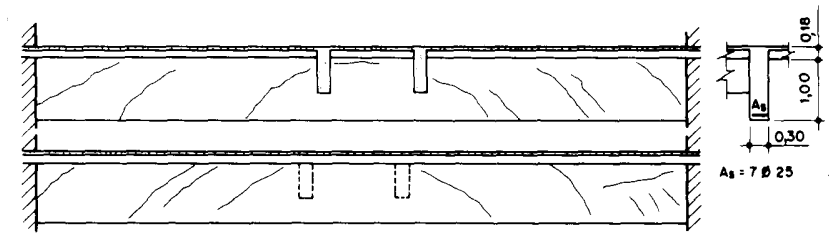

Ejemplo de fisuras en croquis 
Así, por ejemplo, donde el peticionario veía «grietas inclinadas" el informe puede hablar de "fisuras con anchos del orden de media décima de milímetro, de aspecto limpio y bordes agudos, buzando hacia los apoyos con inclinaciones entre los 30 y los 45 grados».

Por cierto, y ya que hablamos de grietas y fisuras, quizá interese que yo revele cuál es la diferencia entre ambos conceptos. Según un colega boliviano que me instruyó en ello, fisura es lo que surge en una estructura calculada o construida por nosotros y grieta lo que surge en una estructura calculada o construida por un colega.

A lo largo de las descripciones conviene, en mi opinión, ir preparando el terreno para lo que se dirá en el apartado 6 acerca de causas posibles y su valoración. No se trata de engañar, advierto, sino de aprestar psicológicamente al lector para que se vaya orientando en la dirección por la que luego discurrirá el informe. Imaginemos un caso de fisuras con ancho en torno a $0,15 \mathrm{~mm}$. Tras estudiar el caso, el patólogo ha podido llegar a la conclusión de que no son peligrosas (supuesto $A$ ), o de que sí lo son (supuesto B), conclusión que el lector ignora por el momento. Pues bien, considérense las dos frases siguientes:

A) «Aparecen fisuras cuyo ancho, en general, no rebasa los $0,15 \mathrm{~mm}$.

B) «Aparecen fisuras cuyo ancho, en general, alcanza los $0,15 \mathrm{~mm}$ e incluso los supera en algún caso".

Una misma realidad reflejada en dos frases diferentes puede inducir en el lector una impresión tranquilizadora o levemente inquietante.

\section{Apartado 5.-Análisis y cálculos realizados}

Se reseñan en este apartado las determinaciones efectuadas en laboratorio (análisis químicos, ensayos mecánicos, etc.) y en gabinete (cálculos), remitiendo a los oportunos Anejos. Las descripciones deben ser breves y precisas, citando las normas y procedimientos adecuados (caso de análisis y ensayos), así como las hipótesis admitidas en los cálculos.

Los resultados deben darse en forma neutra, sin juicios de causa u origen, los cuales figurarán en el apartado siguiente.

\section{Apartado 6.-Causas posibles}

Este apartado, junto con los dos que le siguen, es el más importante del informe. Los tres deben engarzarse adecuadamente y constituir como una sinfonía que discurra de lo general a lo particular, de lo abstracto a lo concreto.
Al hablar de causas posibles sería un error ir derechos al grano. Al principio debe abrirse el gran angular y efectuar un análisis de todas las causas y concausas que han podido influir en el problema. Algunas se mencionarán para ser desechadas de inmediato, quizá en base a los resultados que figuran en el apartado 5 anterior. En realidad, estos resultados deben ser aquí comentados en su totalidad, ya que de no hacerlo con alguno ese tal quedaría en el aire (¿para qué se hizo esa determinación? se preguntaría el lector). Se trata de enriquecer el análisis, de que ninguna de las posibilidades razonables deje de ser explorada. Todo ello, naturalmente, de manera equilibrada y con buen juicio, sin caer en obviedades que empañarían la calidad del informe.

Al final del apartado conviene recoger, en un párrafo de cierre, la esencia de nuestro dictamen en lo que a causas se refiere. Por ejemplo:

«En definitiva, que la causa más probable de las lesiones hay que buscarla en..., sin que pueda descartarse la influencia de otras causas menores tales como... y...».

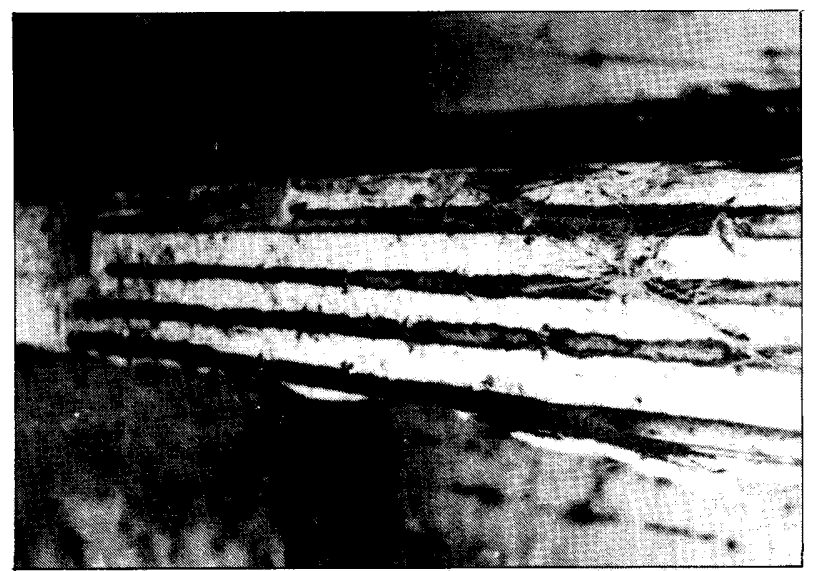

\section{Apartado 7.-Recomendaciones de actuación}

En este apartado se incluyen aquellos consejos que nos parezcan adecuados para seguir adelante hacia una solución definitiva del caso en estudio. Tales consejos puêden referirse a la conveniencia de:

a) Estudiar más a fondo el problema, encomendando a un laboratorio especializado la realización de...

b) Vigilar la evolución de las fisuras y aguardar hasta que...

c) Eliminar la causa que originó el problema, procediendo a...

d) Combatir la causa que originó el problema, efectuando...

e) Realizar un estudio de refuerzo de tales y tales elementos...

f) Etcétera. 


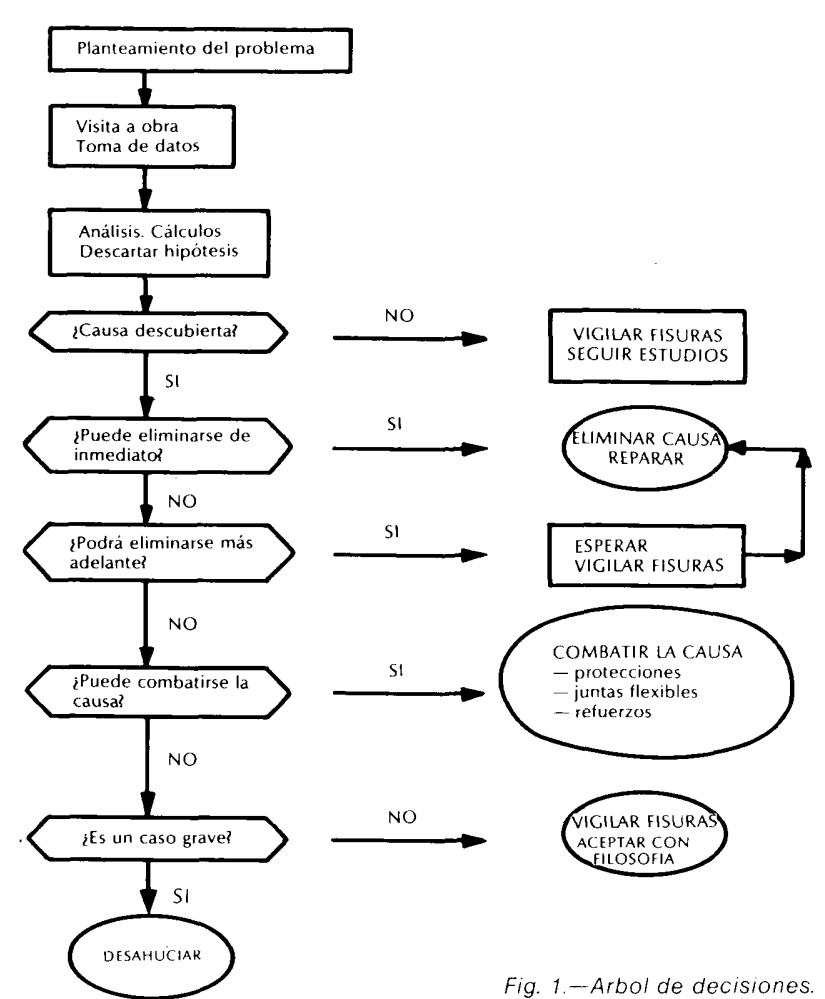

Fig. 1.-Arbol de decisiones.

En la figura 1 se resumen esquemáticamente las variantes que pueden presentarse en un caso general y los distintos escalones de tiempo en que puede situarse nuestro informe.

\section{Apartado 8.-Conclusiones}

Aun cuando, técnicamente hablando, este apartado puede tener una importancia menor que los dos anteriores, desde el punto de vista jurídico es, sin duda, el más importante. Por ello, hay que extremar el cuidado en su redacción, sopesar cada palabra y no abusar de los adjetivos para no invadir el terreno propio de los abogados. Recordemos que éstos suelen leer únicamente las conclusiones, por lo que deberemos exponer aquí la verdadera almendra del asunto.

Hay dos formas de encarar este apartado. En una, las conclusiones son un mero resumen del informe y no contienen información nueva; en la otra, preferible a mi juicio, las conclusiones añaden algún matiz nuevo a lo ya conocido por un lector meticuloso. En cualquiera de ambos casos, conviene redactarlas brevemente (de forma que cada una de ellas contenga un sólo párrafo) y numerarlas correlativamente para facilitar su referencia. Salvo en casos complicados, no deberían ocupar más de una página, o dos a lo sumo.

Para su buena comprensión convendrá, a veces, que vayan precedidas de un preámbulo. En tales casos el.apartado puede titularse «Resumen y conclusiones».
El criterio para redactar y ordenar en conclusiones la información apropiada puede ser diverso. Un criterio lógico es presentar las conclusiones por orden de importancia, es decir, de que sean más o menos relevantes desde el punto de vista técnico, pudiéndose escoger un orden creciente o decreciente. Ahora bien, si se trata de un informe de parte, debe prestarse atención a otra variable que, de manera obligada, jugará en el asunto. Me refiero al aspecto más o menos favorable que cada conclusión presente para nuestro cliente, aspecto que, en alguna medida, puede resultar influido por el orden en que se suministre la información. En este sentido (ver figura 2) una cadencia como la presentada en a) resultará normalmente más perjudicial que la presentada en b). En mi opinión personal la cadencia c) es la más conveniente.
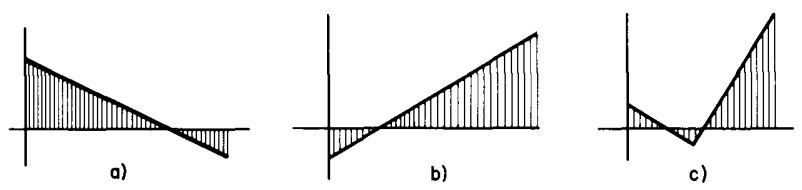

Fig. 2.-Distintas cadencias de las conclusiones.

\section{Colofón del informe}

Acabadas las conclusiones hay que terminar con un colofón previo a la firma. Cuando el autor es un Centro u Organismo, el texto suele tener el siguiente aire:

«Este expediente consta de .... páginas, ...... figuras $y . . . .$. fotografías, numeradas y selladas». Fecha, firma y sello.

Cuando el autor es un profesional, el expediente puede rematarse con una fórmula análoga a la utilizada en informes jurídicos. Por ejemplo:

«El presente dictamen, que consta de .......y de ....... Anejos, contiene la opinión del firmante con arreglo a su leal saber y entender, opinión que gustosamente somete a cualquier otra mejor fundada». Fecha y firma.

Si el informe hubiese sido encargado de oficio por un juez para mejor proveer, pudiera suceder que los gastos ocasionados por el mismo (incluyendo honorarios) no se pudiesen hacer efectivos hasta la sustanciación del litigio, momento en el que una de las partes resultará condenada al pago de las costas. En tal caso, es recomendable hacer figurar el siguiente párrafo detrás de la firma:

«A los efectos oportunos se hace constar que el importe de este expediente asciende a la cantidad de...». 


\section{Algunos recursos lingüísticos}

Como cualquier otra expresión de la conducta humana, la emisión de un informe es un acto que refleja la personalidad del autor. Cada cual tiene su forma de escribir y no se trata aquí de dar lecciones. No obstante, es un hecho que las primeras veces que uno tiene que redactar un informe, suelen aparecer dificultades de expresión, debidas, sobre todo, a la falta de experiencia. Por ello, ofrezco a continuación una pequeña panoplia de frases y palabras para posible beneficio de jóvenes patólogos. Van sin orden, en plan totum revolutum y llevan la intención añadida de despertar un efecto creador por asociación de ideas.

- Fisuras vivas, muertas, limpias, sucias, jóvenes, viejas, originadas por, expresivas de, que buscan el apoyo, intergranulares, transgranulares, cosidas por barras o al aire, aisladas, en grupo, teoría de fisuras, rítmicas, aleatorias.

- Es posible que, es probable que, es verosímil que, es evidente que.

- Ignorancia, duda razonable, conjetura, opinión fundada, certeza.

- Con gran probabilidad, probablemente, con probabilidad no despreciable, con alguna probabilidad.

- No puede descartarse la hipótesis de que...

- No está demostrado que... pero...

- Con objeto de comprobar si... se efectuaron los siguientes...

- A la luz de los resultados obtenidos cabe afirmar...

- No cree el firmante que...
- En el estado actual de los conocimientos no es posible...

- Con las técnicas disponibles no ha sido posible...

En particular, las dos últimas frases pueden servirnos para adornar nuestra ignorancia en puntos cuya piadosa omisión (siempre preferible) nos parezca imposible o deshonesta.

Según el grado de certeza sobre un asunto en el que debamos reseñar también la zona de sombra, nos convendrá construir la frase colocando:

a) primero la duda y después la afirmación, si nos conviene destacar ésta; o

b) primero la afirmación y después la duda, si preferimos subrayar la duda,

ya que, como es sabido, lo último que se lee o escucha de cada frase es lo que más queda latente en el ánimo del lector. Por ejemplo:

a) Aún cuando no puede descartarse que..., la causa principal debe asignarse a...

b) La causa principal debe asignarse a..., aún cuando no puede descartarse que...

Finalmente, y recordando las enseñanzas de la lógica formal, observemos que cuando hay dos contrarios aparentemente excluyentes, A y B, suele convenir más negar $B$ que afirmar $A$, ya que de este modo la gama intermedia de grises queda a nuestro favor. Si además introducimos algún adjetivo de por medio, la cuestión puede alcanzar tantos matices como nos parezca necesario. Considérense, a título de ejemplo, estas dos frases:

A) «es una fisura típica del estado plástico», y

B) «no es una fisura típica del estado endurecido", y repárese en que, con la frase $B$, estamos amparando estas tres posibilidades: que sea una fisura del estado plástico, típica o no; y que sea una fisura no típica del estado endurecido. 


\section{PARTE II.-EL LENGUAJE COMO TRAMPA}

\section{Presentación}

La primera función del lenguaje consiste en ser el principal vehículo de comunicación entre las personas. Desde esta óptica, la lengua es como un producto acabado que recibimos de las generaciones anteriores, producto que nosotros retocamos (no mucho, la verdad) y transmitimos, a nuestra vez, a los que nos siguen. Todo esto es bastante obvio.

Si miramos ahora al lenguaje no como producto, sino como energía (esto es, como sujeto activo) reconoceremos la función que desempeña como conformador básico de nuestra mente, de nuestro modo de aprehender el mundo que nos rodea, de nuestra manera de pensar y razonar. Gracias al lenguaje, en efecto, nacemos a la vida inteligente; y el lenguaje imprime en nosotros unas coordenadas de base, una especie de orientación isotrópica que nos acompañará toda la vida, de la cual no podemos salirnos y, lo que es más importante, de la que no somos conscientes.

La primera vez que entramos en contacto con algo podemos captar ese algo en su auténtica realidad, sobre todo si todavía no tiene nombre. En cuanto aparece el nombre, la etiqueta lingüística, éste se fija en nosotros; y para lo sucesivo, nuestra relación con ese algo se establecerá a través de dicha etiqueta, con lo que las experiencias individuales se transformarán cada vez más en clichés convencionales. Como, por otra parte, cada etiqueta lingüística trae consigo una nubecilla de ideas asociadas, toda esta parafernalia psicolingüística (cuyos aspectos positivos son indudables, dada la economía que entraña) actuará de barrera entre el mundo real y nosotros.

En este mecanismo brevemente descrito se esconden peligros que nos afectan en todo orden de cosas. Por ello, un cierto número de los accidentes que acaecen en la vida no son ajenos a fenómenos lingüísticos; y hay que pensar que lo mismo puede suceder en construcción. Conviene estar alerta.

\section{Un ejemplo banal: la ola}

Para ilustrar lo dicho, fijémonos en lo que sucede con las olas del mar. Toda persona culta sabe que una ola es un fenómeno vibratorio en el que no se produce desplazamiento horizontal de partículas. Sin embargo, la impresión del observador es la de una masa de agua que avanza, impresión reforzada por el hecho de que aludimos al fenómeno utilizando un sustantivo (la palabra ola), es decir, un elemento gramatical propio para designar sustancias.
Sin embargo, la ola es más una acción, un fenómeno, que una sustancia, por lo que la etiqueta lingüística que mejor le cuadraría sería un verbo y no un nombre*. Si la ola se llamase ONDEAR, valga como ejemplo («imira que ondear tan grande!»), posiblemente los profesores de física elemental encontrarían menor dificultad en explicar a sus alumnos el fenómeno ondulatorio y éstos, a su vez, asimilarían más fácilmente y sin sorpresa tan simple enseñanza.

Benjamín Lee Whorf, un lingüista norteamericano que también era ingeniero, analizó estos fenómenos en relación con la que fue su ocupación principal: inspector de accidentes en industrias, por cuenta de una compañía de seguros. El nos relata varios casos de accidentes en los que, a su juicio, jugaron esas asociaciones rutinarias creadas por el lenguaje. He aquí uno de ellos.

En el patio de una fábrica de curtidos de pieles existía una balsa de agua a la que se arrojaban desperdicios de animales. Parte de la balsa estaba cubierta con una gran tapa de madera. Cierto día, un soldador que trabajaba en este patio tiró la cerilla con la que había encendido un soplete a lo que él pensaba que era un "estanque de agua». Pero los desperdicios de animales en descomposición habían originado una gran cantidad de gases que formaron bolsa bajo la tapa de madera. En consecuencia, se produjo una explosión que originó el incendio de la fábrica.

La etiqueta lingüística «estanque de agua» que vino a la mente del operario en el momento de arrojar la cerilla impidió la posibilidad de cualquier tipo de análisis. Captamos algo, le damos un nombre y, a partir de ese momento, el nombre bloquea cualquier otra percepción o punto de vista sobre ese algo.

Pasa un camión cargado de sustancias minerales duras y compactas. Piedras, es la voz interior que, a su vista, surge en el distraído paseante; grava, salia el vocablo, a los labios casi, del estudiante de ingeniería asomado al balcón; rocalla, cruza el término la cabeza del jardinero que anda en moto; proyectiles, piensan gozosos los huelguistas vecinos que andan a palos con la policía. Cada cual ha etiquetado la misma realidad exterior con diferente rótulo lingüístico. Y cada uno de esos rótulos llena la mente del individuo, impidiéndole captar otros aspectos del mismo asunto.

Esta función limitadora del nombre nos puede jugar muy malas pasadas.

\footnotetext{
* Los cuatro conceptos, "sustancia», "acción-fenómeno», "modo" y «relación», agotan el mundo pensable y expresable (si expresable por ser pensable o a la inversa, es cuestión para los filósofos); y a esos cuatro conceptos corresponden en el plano verbal estas clases de palabras: nombre, verbo, adjetivo-adverbio y preposición-conjunción. (María Moliner).
} 


\section{Un ejemplo real}

Debo al profesor José Calavera el conocimiento de un caso patológico real en construcción que me parece especialmente clarificador de estos fenómenos. Se trata de la estructura esquematizada en la figura 3, compuesta por una serie de pórticos que reciben un forjado resuelto con piezas prefabricadas en forma de pí. Este forjado apoya en vigas transversales embrochaladas al pórtico cerca de los apoyos. La estructura estaba sometida a cargas de tráfico urbano con posibilidad de paso de vehículos muy pesados y pronto presentó la fisuración indicada en la figura, en las zonas acarteladas, con anchos superiores al milímetro.
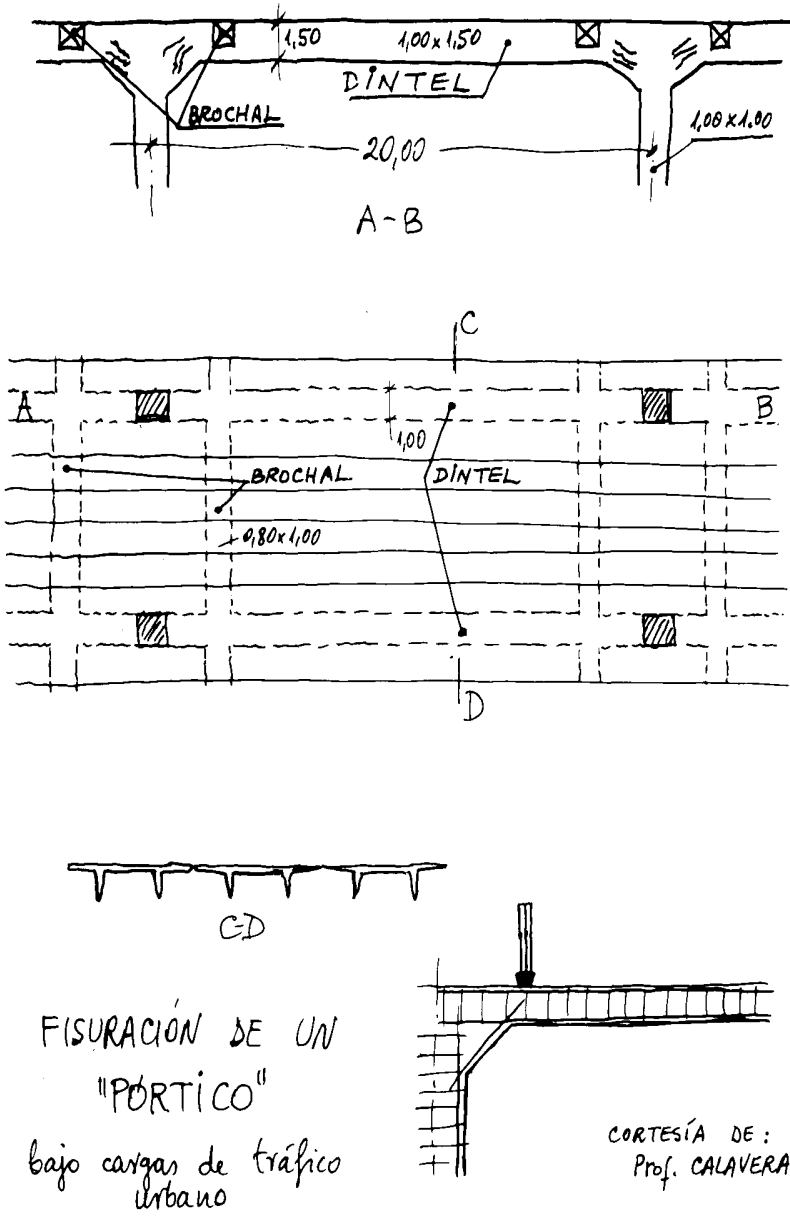

Fig. 3

Obsérvese que los dinteles apenas reciben cargas: tan sólo su peso propio y la poca carga que puede actuar directamente aplicada sobre su anchura. Las cargas variables, en realidad, viajan a través de los brochales hacia las zonas vecinas de los soportes provocando enormes momentos de apoyo, en tanto que los momentos de vano son casi despreciables.
Pues bien, la estructura fue designada como pórtico desde el principio y fue calculada como tal, armándola a cortante, tanto en las zonas de cartelas como en el resto de la luz, por medio de estribos verticales, más la armadura de piel reglamentaria. Sin embargo, el funcionamiento real de esta estructura es el de dos ménsulas sometidas a fuertes cargas concentradas; y ya sabemos que los estribos verticales no son operantes en ménsulas (Fig. 4). Hubo que inyectar resina y reforzar con chapas verticales, con el consiguiente coste.
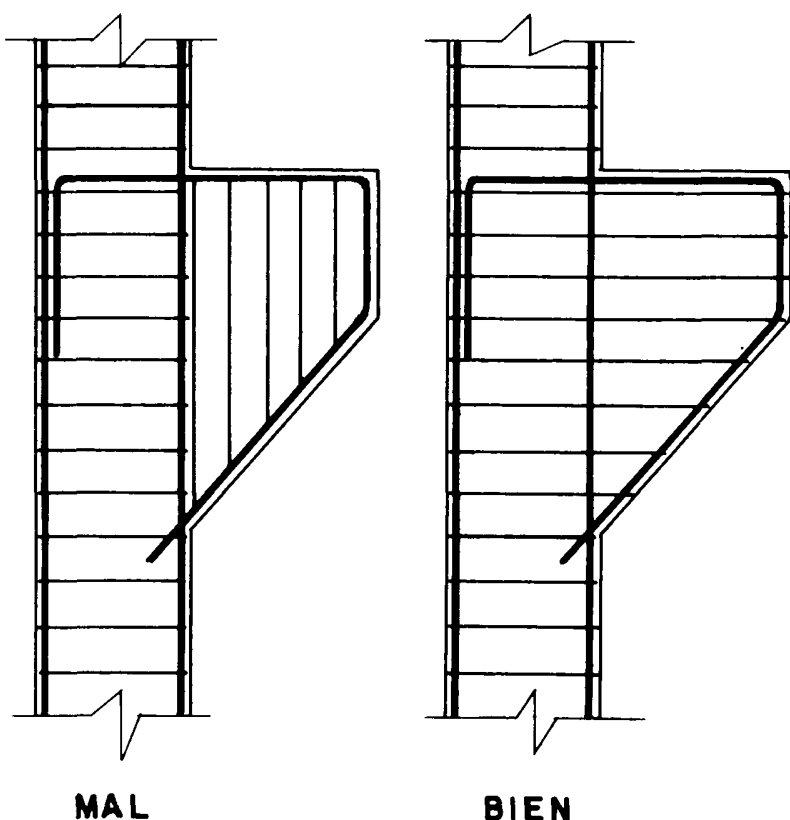

Fig. 4-Armado a cortante en ménsulas

El «bloqueo mental» del proyectista provocado por la etiqueta lingüística pórtico fue, sin duda, el causante del error.

Bloqueos parecidos pueden presentarse en cualquier momento. Así, por ejemplo, la palabra vacío trae consigo una serie de connotaciones tales como hueco, falto de peso, falto de cargas, etcétera, que nos pueden jugar una mala pasada al analizar cierto tipo de estructuras, tales como la losa de fondo de un depósito construido sobre el terreno, la cual recibe un empuje de éste más desfavorable a depósito vacío que a depósito Ileno. Una asociación rutinaria e indebida entre los conceptos soporte, vertical y junta horizontal de hormigonado, fue el origen de un problema serio durante la construcción de un hotel en la Costa del Sol cuyos soportes tenían forma de uve, con lo que aparecieron esfuerzos rasantes indeseables en las juntas mal orientadas (Fig. 5). Los ejemplos podrían multiplicarse. 

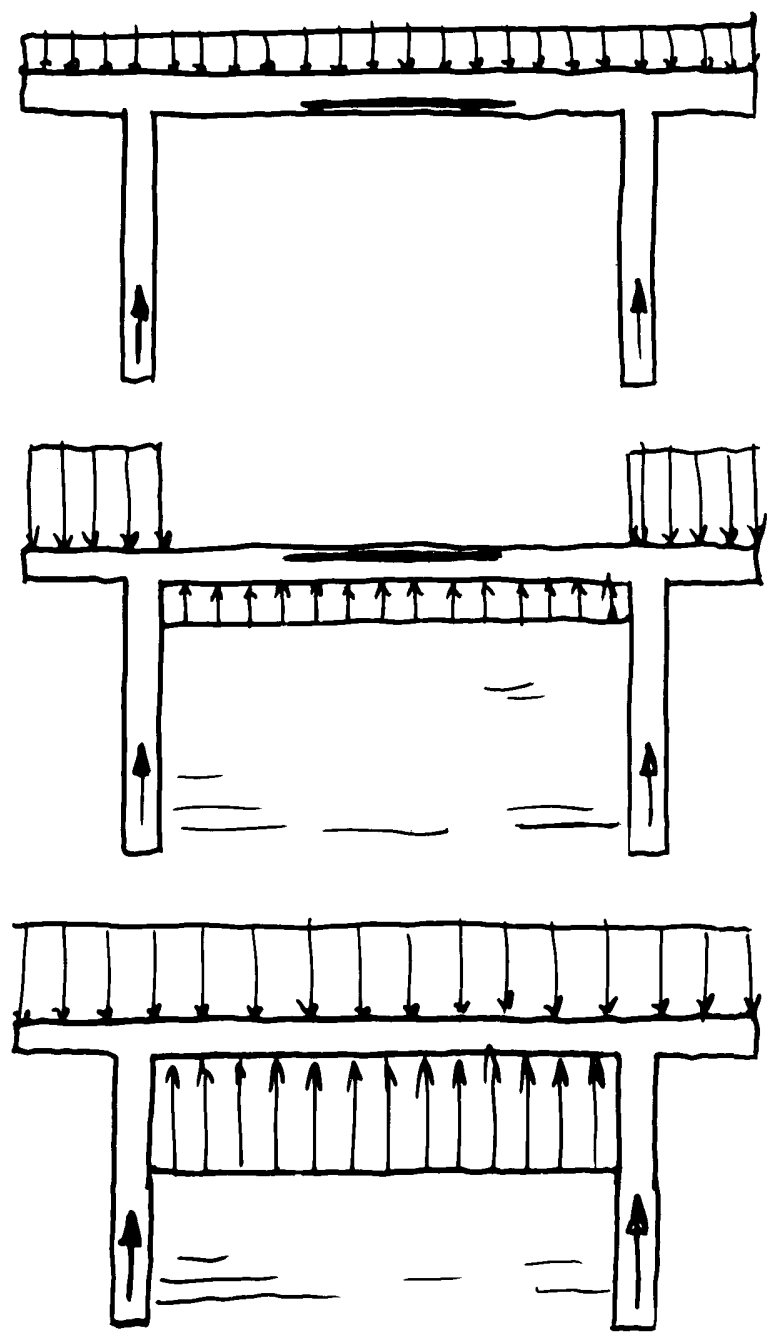

Una peligrosa connotación de la palabra VACIO

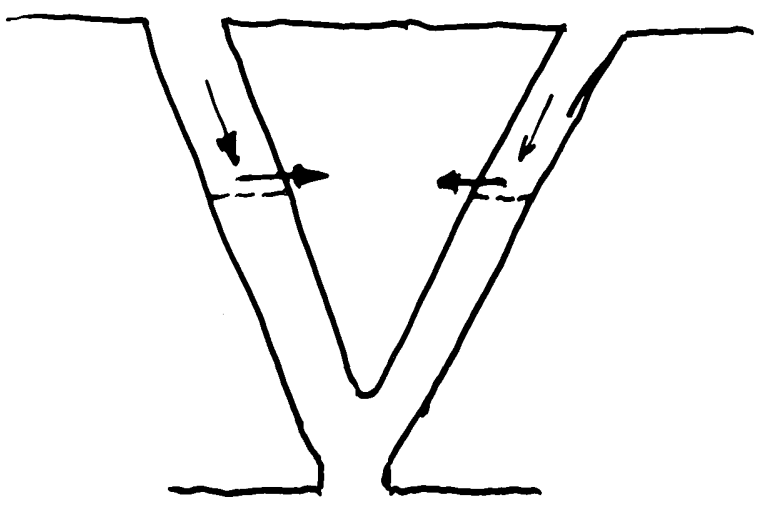

Una asociación rutinaria entre

los conceptos:

- SOPORTE

- VERTICAL

- JUNTA HORIZONTAL

\section{A modo de conclusión}

La patología de la construcción viene originada por la comisión de errores. Los errores pueden cometerse en cualquiera de las fases del proceso constructivo (planeamiento, proyecto, materiales, ejecución, uso) y pueden ser de tres tipos: técnicos, de organización y personales. Los errores técnicos son más fáciles de prevenir (a través de medidas adecuadas de control de calidad) y son el origen de un 20 por 100 de los casos de patología, aproximadamente. En cambio, los otros dos tipos de errores (personales y de organización-gestión) son el origen del 80 por 100 de los casos y son más difíciles de prevenir, entre otras razones porque se han estudiado poco hasta el presente. Por eso, la prevención de errores en construcción pasa hoy (y pasará más cada día) por una zambullida de los ingenieros en el campo de las humanidades. La frontera entre ciencias aplicadas y ciencias sociales ha perdido ya su sentido.

En la base de este nuevo mundo unitario se coloca el lenguaje. Reflexionar sobre él y mirar la realidad cotidiana con ojos nuevos son actualmente dos necesidades en cualquier actividad científica.

\section{Nota final}

El autor agradecerá el envío de comentarios, ejemplos y sugerencias en relación con la Parte $\|$ de este artículo, ya que se encuentra trabajando en la materia y desea profundizar en ella. Escribir al Instituto Eduardo Torroja, Apartado 19002, Madrid.

\section{Bibliografía}

- «Lenguaje, pensamiento y realidad» de Benjamín Lee Whorf. Barral Editores, Barcelona, 1971.

- «Lenguaje, pensamiento y realidad». Capítulo III del libro "Lenguaje y discriminación sexual» de Alvaro García Meseguer. Segunda edición en Montesinos Editor, Barcelona, 1984. 